\title{
The effect of reflective garden walking on improving quality of life, hopefulness and personal growth
}

Volume 5 Issue 2 - 2017

\section{Introduction}

Most people around the world face everyday stressors that over time can be overwhelming and create both physiologic and psychological health issues. ${ }^{1}$ Stress can be defined as a process in which environmental demands strain an organism's adaptive capacity, resulting in both psychological demands as well as biological changes that could place it at risk for illness. ${ }^{2}$ In a survey of health and stress in America, the American Psychological Association (2011) found that several groups have a higher risk for health related issues due to stress, including caregivers, those who have lost loved ones, and those with serious illnesses, obesity, or depression. Forty-four percent of respondents in this survey reported that their stress level increased in the last year while only $17 \%$ reported a decrease in stress levels. Less than half of the respondents in this survey said they were effectively preventing stress, and a majority of respondents felt that stress had a very strong impact on their personal health. Increasing stress can make existing health problems worse, and the longer stress interferes with the ability to live a normal life, the more dangerous it becomes to physical and mental health. ${ }^{3}$

Some diseases are more prone to be affected by stress or the lack of stress than others. For example, stress has been shown to increase arthritis pain, lower back pain, headache, asthma symptoms, and the risk for common viral infections such as a cold ${ }^{4}$ However, positive feelings that reduce stress can improve health. In one study, ${ }_{5}^{5}$ patients with positive affect, such as feelings of joy, peace and trust, were found to have reduced levels of heart disease. Specifically, this study demonstrated that for every one-point in positive affect on a fivepoint scale, the rate of heart disease dropped by 22 percent. Stress can increase corticosteroid levels that lower the effectiveness of the immune system and therefore lower the body's ability to fight off infections. ${ }^{6}$

Brendel (2014) studied behaviors that reduce stress, including reflection, and recommends three ways to manage stress using reflection. The first is to reflect on core strengths and resources by reviewing life goals and building a positive relationship with you. The second is to reflect on your personal list of fundamental values to define life goals and how to achieve them, despite stressful situations, and the third is to engage in self-reflection frequently to "check in" with yourself to put life in perspective. Brendel states that "everyone can benefit from sustained reflection both as a good think in itself and as a powerful stress management tool" (2014, p 15).

There are methods for reducing stress and the problems associated with stress that has been shown to be effective. Being reflective or mindful is a way of thinking about and analyzing experiences that can reduce stress. Mindfulness allows one to make sense of past experiences, resolves the way past problems are viewed, and allows for thinking positively as successes in life are remembered. Reflection encompasses more than remembering and attempts to move beyond simply describing events. It allows for analysis, honesty, and distance from experiences and ideas. It can allow a person to create conclusions

\author{
Ruth Ruth McCaffrey,' Kelly J McCaffrey, ${ }^{2}$ \\ Sally Schauman ${ }^{3}$ \\ 'Georgia Baptist College of Nursing of Mercer University, \\ Georgia \\ ${ }^{2}$ Assistant Professor, 1000 University Center Lane, Georgia \\ ${ }^{3}$ Adjunct Professor, Duke University, USA
}

Correspondence: Ruth McCaffrey, Professor, Georgia Baptist College of Nursing of Mercer University, 300I Mercer University Drive, Atlanta, Georgia, Email mccaffy_rg@mercer.edu

Received: October 24, 2016 | Published: January 24, 2017

based on reflective processing and plan for actions to reduce stress and anxiety in everyday life events. Reflection, therefore, can help people to learn from their mistakes, create ideas, make sense of life issues over which there is no control, increase happiness, and provide a positive perspective on life.

Currently, very few Americans use reflection or mediation in daily life. Clarke et al., ${ }^{7}$ conducted a national survey and found that only $8 \%$ of Americans practice mindfulness, mediation, or reflection. Reflection is a first step toward mindfulness and meditation. Rather than emptying the mind for medication, reflection calls for one to contemplate, deliberate, and ponder events and life situations. It is important to be able to focus on the reflection rather than ruminate over current problems and schedules. One of the difficulties in beginning a reflective practice is learning how to quiet the daily thoughts and plans that run through the mind and begin to be aware of surroundings in the moment. Experiences and lessons in reflection are not common and often assume that the person has a history of being reflective. ${ }^{8}$ Working with reflection and mindfulness as meditation should be gradual and start with a purpose in mind to prevent disengagement or reduced interest.

One of the ways to successfully begin a reflective practice is through spending time in nature and allowing the peaceful, green spaces to provide a opportunity for natural reflection. ${ }^{9,10}$ Biophilia, a term first described by Wilson, ${ }^{11}$ refers to the positive connection between humans and nature. Several studies have found that connectedness with nature increases both psychological and social wellbeing. ${ }^{12,13}$ Mayer et al., ${ }^{14}$ found that being connected to the natural world increased wellbeing and provided a more positive affect. Some of the physical effects of spending time in gardens includes lower blood pressure, lower levels of blood glucose in diabetics, and increased strength of the immune system. ${ }^{15-18}$

\section{Study}

To better understand the benefits of reflection and connection to nature, a study was designed using a reflective garden walking 
programming entitled "Stroll for Wellbeing" (Stroll). The Stroll was conducted at two different gardens. The first was the Morikami Japanese Gardens in Delray Beach Florida (data collected from 20082011 ) and the second was the Bloedel Reserve on Bainbridge Island Washington (data collected from 2014-2016). Both gardens are open to the public and were created with the intent to be healing garden sites. The walks at each garden asked participants to complete 12 themed walks, stopping in spots for reflection and short readings related to the themes to stimulate reflection. The themes for the 12 walks were the same at both gardens; however, the walking guides were specific to each garden. Each of the gardens continues the Stroll program, and both have waiting lists for those who wish to participate. Funding for both of these projects came from private and corporate donors. The Morikami Stroll is supported by the Astellas Pharmaceutical Company in Japan. The Bloedel walks are supported by the Kitnap Cancer Center and other local healthcare agencies.

Participants for this study were recruited through each garden's newsletter and lectures to several groups in each community. After the first stroll programs, newspaper articles were published about the stroll programs. Each of the gardens had a designated employee to enroll stroll participants via email or telephone call and to communicate reminders of meetings with them. Once enrolled, participants were placed into groups of 20-25 participants. Four groups were started at a time; two groups met on two successive mornings and two groups on successive afternoons. At the Morikami, strolls began in October, January and March. At the Bloedel, strolls began in April, June and August.

The Stroll is an 8-week program with 12 themed walks, three group meetings, and a guide (journaling) book. Each individual stroll group has between 20 and 25 members. During the first meeting, the participants sign informed consent, receive their stroll book and journal, and learn about the stroll and their participation. At the Morikami, all twelve walks are on a circular pathway around the garden with each themed walk having the same 6 stopping spots. At the Bloedel Reserve on Bainbridge Island, Washington, the garden is much larger, and therefore, four different walking paths are used. Participants are directed in the stroll guide and journal to do three themed walks on each of the four paths in the garden with 6 stopping spots on each path. The themes for each garden walking program are the same. Table 1 presents the themes for the stroll walks. For each themed walk at each stopping spot, there are short readings to encourage reflection about the garden and the theme of the walk. Table 2 provides examples of stopping spots and short readings.

Table I Themes for stroll walks

I. Awareness
2. Joy
3. Possibility
4. Freedom
5. Transition
6. Forgiveness
7. Connection
8. Reflection
9. Journey
10. Gratitude
11. Trust
12. Fulfillment

During the first meeting, participants are told that the twelve themed walks are to be done individually, whenever the gardens are open. The themes, stopping spots, and journal pages are reviewed with participants. The second and third meetings are simply to share experiences in the garden walks with other members of the group. The participants are told that no one will ever ask to see their garden walking book and journal and that it is a private place for them to write thoughts and feelings related to the walks and themes. During the group meetings, participants are asked if they wish to share, and many of them share their experiences about the reflective garden walks. They speak about a newfound connection with a larger world that is nature, a world that enfolds them and provides peace and serenity.

\section{Research design}

The study used a quasi-experimental one group design to determine the effect of the Stroll for Well-Being on participants at the Morikami Japanese Garden in Florida and the Blooded Reserve Garden on Bainbridge Island, Washington. Participants were asked to complete the three outcome measures and a short demographic survey prior to beginning the program and to complete the three outcome measures at the end of the eight-week walking program. During the slotted study time, there were 195 participants at the Morikami Japanese Garden who completed the walks and all the outcome measures. At the Bloedel, there were 209 participants who completed the eightweek program and all of the outcome measures. Table 3 provides the demographics of each group.

Paired T tests were used to determine the change in each of the outcome measures between the pre- and post-test. The scores for participants at each garden were done separately and then in the aggregate. Tables $4 \& 5$ present the data and analysis.

\section{Outcome measures}

Along with a short demographic questionnaire, three measurement tools were used to collect data from the participants. These were the Personal Growth Initiative Scale (PGIS), Hope Scale, and the Quality of Life Scale. Each participant completed the three scales prior to the first stroll meeting and again at the end of the third and final meeting. The PGIS ${ }^{19}$ measures a person's active and intentional involvement in changing and developing as a person. The PGIS consists of nine items that are rated on a Likert-type scale from $1=$ strongly disagree to $6=$ strongly agree. Item scores are summed to obtain a total PGIS score. There is evidence that the PGIS is strongly and positively related to psychological well-being and negatively related to psychological distress. A confirmatory factor analysis with three independent samples of community participants yielded Cronbach's alpha of .65. The test-retest reliability over 1-, 2-, 4-, and 6-week periods and tests of concurrent and discriminant validity using samples of college students yielded Cronbach's alpha of $.77 .{ }^{20}$ This is consistent with the original measures of validity completed in earlier studies. ${ }^{21}$

The Adult Hope $\mathrm{Scale}^{22}$ is a 12 -item scale with two subscales for pathways thinking and future thinking. Participants respond to each item using an 8-point scale ranging from definitely false to definitely true. The pathway subscale determines a person's ability to use hope in daily thinking and planning. The future subscale determines the ability of the participant to see hope in the future.

Babyak et al., ${ }^{23}$ studied the Adult Hope Scale, including the two subscales for reliability and validity. It was found to have high levels of test-retest validity in a group of 249 adults in New England (p $=.01$ ). In this same study, internal consistency and reliability were 
measured and the entire scale was found to have Cronbach's alpha of .63 , while the alpha was .66 for the pathways subscale and .61 for the future subscale.

The Quality of Life Scale in adults with chronic illness ${ }^{24,25}$ is a 16-item scale measuring quality of life in those who have chronic illnesses or stressors. The scale has demonstrated reliability and validity in a large number of clinical trials and studies in many different populations. Estimates from a study of 240 American patients with chronic illness (diabetes, osteoarthritis, rheumatoid arthritis, and post ostomy surgery) indicated that the 15-item Quality of Life Scale satisfaction scale was internally consistent $(\alpha=.82-.92)$ and had high test-retest reliability over 3 weeks in stable chronic illness groups ( $\mathrm{r}$ $=.78-.84){ }^{26}$

Table 2 Examples of themes and readings

\begin{tabular}{|c|c|c|c|c|}
\hline Themes & \multicolumn{4}{|l|}{ Readings } \\
\hline & \multicolumn{4}{|c|}{$\begin{array}{l}\text { "Breathing in, I calm body and mind. Breathing out, I smile. Dwelling in the present moment, I know this is the only moment." } \\
\text {-Thich Nhat Han, Philosopher }\end{array}$} \\
\hline Awareness & \multicolumn{4}{|c|}{$\begin{array}{l}\text { Be aware of all that is around you. Be fully present in the moment. Put all other thoughts out of your mind. The Buddha said: } \\
\text { "If we could see the miracle of a single flower clearly, our whole life would change" Become aware only of what you are doing, } \\
\text { seeing, feeling, and sensing at the present moment. }\end{array}$} \\
\hline Possibilities & \multicolumn{4}{|c|}{$\begin{array}{l}\text { Possibilities lie in each moment; the limitations lay only in our minds. As you begin this walk today, consider the many possibilities } \\
\text { open to you, and your many opportunities for happiness and joy. Remember dreams are renewable, no matter what your age or } \\
\text { situation. Untapped possibilities are still within you. New beauty is waiting to be born. }\end{array}$} \\
\hline Journey & \multicolumn{4}{|c|}{$\begin{array}{l}\text { "A journey is a person in itself; no two are alike. And all the plans, safeguards, policing, and coercion are fruitless. We find that } \\
\text { after years of struggle that we do not take a trip; a trip takes us." -John Steinbeck. } \\
\text { Think about your journeys. Where has life taken you? The path of life has many twists and turns. No two directions are ever the } \\
\text { same. Joy is found not in reaching the destination, but in the journey itself. }\end{array}$} \\
\hline Reflection & \multicolumn{4}{|c|}{$\begin{array}{l}\text { Albert Schweitzer said "At times our own light goes out and is rekindled by a spark from another person." Each of us has cause } \\
\text { to think with deep gratitude of those who have lighted the flame within each of use. Spending time in nature and strengthening } \\
\text { the connection to nature is one way of rekindling that light of the human spirit.As you sit and reflect, think about the gift we } \\
\text { have of the earth and all of its natural beauty. }\end{array}$} \\
\hline \multicolumn{5}{|c|}{3 Demographic data } \\
\hline \multicolumn{2}{|c|}{ Demographic } & Morikami (195 Participants) & Bloedel (209 Participants) & Total (404 Participants) \\
\hline \multicolumn{2}{|l|}{ Males } & 83 Males $(43 \%)$ & 48 Males $(23 \%)$ & |3| Males $(32 \%)$ \\
\hline \multicolumn{2}{|l|}{ Females } & I I 2 Females $(57 \%)$ & 161 Females $(77 \%)$ & 273 Females $68 \%$ \\
\hline \multicolumn{2}{|c|}{ Mean Age } & 78 & 62 & Total Mean age 7I \\
\hline \multicolumn{2}{|c|}{ High School highest education } & 58 & 21 & $79(19 \%)$ \\
\hline \multicolumn{2}{|c|}{ College Education } & 137 & 187 & $324(81 \%)$ \\
\hline \multicolumn{2}{|c|}{ Married } & $65 \%$ & $56 \%$ & \\
\hline \multicolumn{2}{|l|}{ Widowed } & $14 \%$ & $12 \%$ & \\
\hline \multicolumn{2}{|l|}{ Divorced } & $21 \%$ & $34 \%$ & \\
\hline
\end{tabular}

Table 4 Morikami data

\begin{tabular}{lllllllll}
\hline Measure & N & Range & Pretest M & Post Test M & SD & T & Degrees of Freedom & Significance \\
\hline Hope Scale & 195 & $8-96$ & 43.3 & 50.4 & 7.75 & 3.35 & 194 & .001 \\
Personal Growth Scale & 195 & $9-54$ & 38.8 & 43.7 & 6.6 & 9.3 & 194 & .001 \\
Quality of Life Scale & 195 & $16-112$ & 80.4 & 86.4 & 10.7 & 6.8 & 194 & .001 \\
\hline
\end{tabular}

Table 5 Bloedel data

\begin{tabular}{lllllllll}
\hline Measure & N & Range & Pretest M & Post Test M & SD & T & Degrees of Freedom & Significance \\
\hline Hope Scale & 209 & $8-96$ & 41.7 & 53.2 & 5.49 & 5.6 & 208 & .001 \\
Personal Growth Scale & 209 & $9-54$ & 39.2 & 47.6 & 3.4 & 11.2 & 208 & .000 \\
Quality of Life Scale & 209 & $16-112$ & 79.3 & 89.2 & 4.4 & 8,1 & 208 & .001 \\
\hline
\end{tabular}

\section{Findings}

The demographics of each group were different. The Morikami group was significantly older (Morikami $\mathrm{M}=78$, Bloedel $\mathrm{M}=62$ ) and the Morikmai group had a higher number of males (Morikami Bloedel). It was determined that the reason for this disparity may be that the Bloedel Reserve is in an area of fewer retirees and that more men in that area are still employed. Both participants at Morikami and Bloedel had significant improvements in the scores of all three outcomes measurements, the Hope scale (Morikami $\mathrm{t}=3.35, \mathrm{p}=.001$; Bloedel, $\mathrm{t}-=5.6, \mathrm{p}=.001$ ), the Personal Growth Scale (Morikami, $\mathrm{t}=9.3 . \mathrm{p}=.000$; Bloedel $\mathrm{t}=11.2, \mathrm{p}=.000)$, and the quality of life scale (Morikami, $\mathrm{t}=6.8 . \mathrm{p}=.001$ ' Bloedel, $\mathrm{t}=8.1, \mathrm{p}=.001$ ). While all measures showed statistically significant improvement, the measure that had the most significant change from pre- to post-test was the Personal Growth Scale. The overall focus of the PGS is to measure the willingness of persons to view their lives as they are now and to accept a willingness to change in a growth oriented direction.

In addition to the outcome measures, participants were given an exit survey and asked to comment on the program and how it affected them. The participants at both Stroll sites provided meaningful comments regarding how the stroll affected them personally. 
The following are examples of comments written on the exit survey:

i. This was a gift. No matter how I felt when I started, I always left with Joy.

ii. The beauty of the garden gave me a renewing feeling and a sense that my life was part of a greater plan that was all in order.

iii. By directing my thoughts to positive acceptance of losses of the past and presenting views of the present and future that gave me hope the book was a major part of my feeling better at the end of the 8 weeks.

iv. These walks have opened my eyes about the beauty that surrounds me and puts my problems and fears into a perspective that is easier to live with.

v. Joy helps you to open your mind and clear out negative and confusing thoughts. The whole experience helped me to foucs on the goodness and joy and freedom I have in life.

\section{Discussion}

The purpose of this study was to determine the effect of a 12 walk reflective garden walking program. Two different gardens were used, one in Florida and one in Washington. These 404 participants represented a large segment of society, from two very different parts of the country, and represented people with many different stress related problems. Some of the participants reported PTSD as a primary problem in their lives, some had recently lost a loved one, some had received a diagnosis of a life-threatening health problem or faced disability that restricted their ability to live in a way that they had in the past, some had recently retired and were finding it stressful to "reinvent" themselves in their new life role.

The outcomes of the reflection used in the stroll program were consistent with Brendel's (2014) three steps of reflection for positive health. The participants all remarked on the reflection as a time to review and reinvigorate their core strengths. The improvement in the hope scale demonstrates that participants were able to use the reflection and peacefulness of nature to increase their hope for their future. Discussion in each group focused on the connection with nature as providing a peaceful place in which to being this reflective practice. From the outcomes of the Personal Growth scale it was evident that participants were able to review life goals and plan for positive changes and growth. Finally, in the area of building a positive relationship with self, participants described the garden walking as a time for them alone, where they could come to know themselves at a deeper level.

Participants indicated that they developed a healing relationship with the gardens in which the stroll took place, and looked forward to expanding their reflective practices within the gardens and other gardens in the areas where they lived. Similar to the work of Tokayer, ${ }^{10}$ the participants expressed feelings of resilience to the stressors in their lives as they progressed in their reflective practice and further connected with the garden and nature as a place of serenity, and strength. The positive changes in the Quality of Life Scale also demonstrate that the participants had an overall positive experience that improved the quality of life and reduced stressors.

The implications that come from this study include encouraging reflection, garden or nature walking, and spending time in nature as ways to reduce stress and improve health. This is consistent with the findings of studies on Shinrinyoku. Spending time in natural surroundings can reduce the stress of disease or social issues. Based on outcomes from both Stroll groups over time, physicians in the areas of the two gardens are recommending the Stroll program to patients with stress and anxiety. In addition, the veteran's hospital in both Florida and Washington continue to send veterans with PTSD for the strolls.

The question becomes what if there is no formal Stroll program in the area? Benefits of spending time in nature and journaling about issues that are stress producing can assist in stress reduction without a formal program. The success of the Stroll program, however, has led to beginning programs in several other gardens around the country, most notably in California, Oregon, Chicago, and Tucson, Arizona. Working with mental health professionals, therapists, and other healthcare professionals, the development of a stroll in nature could be designed almost anywhere where there is green space and a pleasant walking environment. ${ }^{27,28}$

\section{Conclusion}

The Stroll for Wellbeing in both the Morikami Garden in Florida and the Bloedel Reserve on Bainbridge Island in Washington have shown that reflective garden walking improved hopefulness, quality of life, and increased the desire for personal growth among 404 people experiencing stressful life situations. The Stroll for Wellbeing is an 8 -week program using 12 themed walks that are completed by participants whenever they are able to spend time in nature. Each walk has several stopping spots where participants can sit and reflect on short readings in the guide book and journal on the pages provided in the guide book. Three meetings are held: one to explain the walks and have participants learns about the garden walks, the second and third to discuss the experiences of the stroll. No one is ever required to speak at the meetings or share their journal; however, it has been noted that most people enjoy sharing and feel strengthened by the sharing of others.

Outcomes measured prior to the stroll and at the end of the 8-week program demonstrate that participation increased hopefulness, created a willingness to make life changes to promote personal growth and generally improved quality of life among participants.

The Stroll for Wellbeing continues to expand to other gardens around the country and can be developed at any green space with easy walking trails. Encouraging patients with high stress levels or those who face stress-related life issues to participate in reflective nature walking and journaling could improve lives, improve quality of life, and reduce stress related morbidity and mortality.

\section{Acknowledgments}

None.

\section{Conflicts of interest}

Author declares there are no conflicts of interest.

\section{Funding}

None.

\section{References}

1. Nilsen C, Andel R, Fritzell J, et al. Work-related stress in midlife and all-cause mortality: can sense of coherence modify this association. Eur J Public Health. 2016;26(6):1055-1061.

2. Cohen S, Kessler RC, Gordon LU. Strategies for measuring stress in studies of psychiatric and physical disorders. 1995. 
3. Denollet J, Schiffer AA, Spek V. A general propensity to psychological distress affects cardiovascular outcomes: Evidence from research on the type D (distressed) personality profile. Circulation. Circ Cardiovasc Qual Outcomes. 2010;3(5):546-557.

4. Cohen S, Deverts D, Doyle W, et al. Chronic stress, glucocorticoids receptor resistance, inflammation and disease risk. PNAS. 2012;109(16):5995-5999.

5. Davidson KW, Mostofsky E, Whang W. "Don't worry, be happy": Positive affect and reduced 10-year incident coronary heart disease: The Canadian Nova Scotia Health Survey. Eur Heart J. 2010;31(9):10651070

6. Kiecolt-Glaser JK, Garner W, Speicher C, et al. Psychosocial modifiers of immunocompetence in medical students. Psychosom Med. 1994;46(1):7-14.

7. Clarke TC, Black LI, Stussman BJ, et al. Trends in the use of complementary health approaches among adults: United States, 20022012. Natl Health Stat Report. 2015;79:1-16.

8. http://www.chopra.com/eel/7-myths-of- meditation

9. Kathleen W. Research on the beneficial aspects of the experience of nature in cities. TKF Foundation, USA.2012.p.1-27.

10. Tokayer D. Building resilience to stress. 2010.

11. Wilson E. Biophilia. USA: Harvard University Press, Cambridge; 1984.p.1-176

12. Cervinka R, Röderer K, Hefler E. Are nature lovers happy? On various indicators of well-being and connectedness with nature. Journal of Health Psychology. 2012;17(3):379-388.

13. Howell AJ, Dopko RL, Passmore HA, et al. Nature connectedness: Associations with well-being and mindfulness. Personality and Individual Differences. 2011;51(2):116-171.

14. Mayer FS, Frantz CM, Bruehlman-Senecal E, et al. Why is nature beneficial? The role of connectedness to nature. Environmental Behavior. 2009;41(5):607-643.

15. Lee J, Park BJ, Tsunetsugu Y, et al. Effect of forest bathing on psychological responses in young Japanese male subjects. Public Health. 2011;125(2):92-100.
16. Ohtsuka Y, Yabunaka N, Takayama S. Shinrinyoku (forest-air bathing and walking) effectively decreases blood glucose levels in diabetic patients. Int J Biometeorol. 1998;41(3):125-127.

17. Park BJ, Tsunetsugu Y, Kasetani T, et al. The physiological effects of Shinrinyoku (taking in the forest atmosphere or forest bathing): Evidence from field experiments in 24 forests across Japan. Environ Health Prev Med Medicine. 2010;15(1):18-26.

18. Quing L. Effect of forest bathing trips on human immune function. Environ Health Prev Med. 2010;15(1):9-17.

19. Robitschek C. Personal growth initiative: The construct and its measure. Measurement and Evaluation in Counseling and Development. 1998;30:183-198.

20. Robitschek C. Validity of personal growth initiative scale scores. Journal of Counseling Psychology. 2003;50(4):496-502.

21. Robitschek C. Further validation of the Personal Growth Initiative Scale. Measurement and Evaluation in Counseling and Development. 1999;31:197-210.

22. Robitschek C. Further validation of the Personal Growth Initiative Scale. Measurement and Evaluation in Counseling and Development. 1999;31:197-210.

23. Bayyak MA, Snyder CR, Yoshinobu L. Psychometric properties of the hope scale: A confirmatory factor analysis. Journal of Research in Personality. 1993;27(2):154-169.

24. Burckhardt CS, Clark SR, Bennett RM. Fibrobyalgia and quality of life. A comparative analysis. J Rheumatol. 1993;20(3):475-479.

25. Burckhardt CS, Woods SL, Schultz AA, et al; Quality of life of adults with chronic illness: A psychometric study. Res Nurs Health. 1989;12(6):347-354.

26. Burckhardt CS, Anderson K. The quality of life scale (QOLS): Reliability, validity, and utilization. Health Qual Life Outcomes . 2003;1:60.

27. Salomon M, Vella A. Stress in America: Our health at risk. USA American Psychological Association; 2011.p.1-78.

28. Cohen S, Kessler RC, Gordon LU. Measuring stress: A guide for Health and Social Scienctists. USA: Oxford: Oxford University; 1995.pp.186. 